\title{
Molecular cloning and characterization of a proline iminopeptidase gene from Neisseria gonorrhoeae
}

\author{
N. H. Albertson* and M. Koomey \\ Department of Microbiology and Immunology, University \\ of Michigan Medical School, 6643 Medical Science \\ Building II, Ann Arbor, Michigan 48109-0620, USA.
}

\section{Summary}

Proline iminopeptidase (Pip) is a hydrolase elaborated by virtually all strains of Neisseria gonorrhoeae that selectively removes $\mathrm{N}$-terminal proline residues from peptides. Escherichia coli clones expressing the gonococcal gene coding for Pip were identified in a genomic cosmid library using a synthetic colorimetric substrate. Nucleotide sequence determination and analyses of polypeptides detected by coupled in vitro transcription/translation reactions revealed that Pip is a 311-amino-acid polypeptide with a $M_{r}$ of $35 \mathrm{kDa}$ and a pl of 5.4. Southern hybridization showed that the pip gene is present in a single copy on the chromosome of $\boldsymbol{N}$. gonorrhoeae strain MS11 which maps immediately upstream of the previously identified opaA locus. The transcriptional start site of pip in $E$. coli, determined by primer extension analysis, was characteristic of an NtrA or sigma-54-dependent promotor. Complementation of an E. coli mutant deficient in both proline biosynthesis and dipeptide uptake confirmed that Pip is capable of releasing biologically active proline from peptides. Pip expression was found to be non-essential for in vitro growth of $N$. gonorrhoeae, based on the viability of a $\mathrm{Pip}^{-}$gonococcal mutant.

\section{Introduction}

Neisseria gonorrhoeae, the causative agent of gonorrhoea, is a highly successful parasite of man. Gonococcal isolates taken from infections often display a prolinerequiring phenotype: as many as 20 to $40 \%$, depending on geographical source (Knapp and Holmes, 1975). The isolation of a proline auxotrophic strain is conclusive evidence of its ability to colonize successfully the human host, suggesting that either exogenous proline is present

Received 23 April, 1993; revised and accepted 1 June, 1993. *Present address for correspondence. Department of General and Marine Microbiology, University of Göteborg, Carl Skottsbergs Gata 22, S-413 19 Göteborg, Sweden. Tel. (31) 7732500 ; Fax (31) 7732599. or that the bacterium has alternative means of acquiring this amino acid critical to its viability. Chen and Buchanan (1980) have described two gonococcal enzymes implicated in proline acquisition: (i) an aminopeptidase $\mathrm{P}$ which cleaves peptides having the structure $X-P r o-Y-Z$ to yield $X+$ Pro- $Y-Z$ where $X, Y$, and $Z$ denote amino acid residues, and (ii) proline iminopeptidase (Pip) which hydrolyses peptides having the structure Pro- $Y-Z$ to yield free proline. Pip was found to release only proline from each of 14 peptides with the structure Pro- $\mathrm{X}, \mathrm{Pro}-\mathrm{X}-\mathrm{NH}_{2}$ or Pro- $\mathrm{X}-\mathrm{Y}$, although its activity appeared to decrease with increasing chain length of the substrate (Chen and Buchanan, 1980).

Proline iminopeptidase activity was first identified in Escherichia coli based on the ability of proline auxotrophs to utilize poly-L-proline as a source of proline (Sarid et al., 1959). The authors described the activity as being highly specific for $\mathrm{N}$-terminal L-prolyl residues, regardless of the chain length of the substrate (Sarid et al., 1959; 1962). Thereafter, the enzyme has been detected in eukaryotic sources, in Bacillus megaterium (Yoshimoto et al., 1980), Bacillus coagulans (Yoshimoto and Tsuru, 1985), and in Lactobacillus casei isolated from the human oral cavity (Mäkinen, 1969). Recently, the gene encoding proline iminopeptidase in $B$. coagulans has been cloned and sequenced (Kitazono et al., 1992).

The detection of Pip activity along with other enzymatic activities using synthetic chromogenic substrates has been used in clinical studies to differentiate $N$. gonorrhoeae from other diplococci (D'Amato et al., 1978; Sperry et al., 1986; Yajko et al., 1984). Results from these studies suggest that Pip may perform an important function for gonococci in vivo since all isolates tested express Pip activity, whereas both $\mathrm{Pip}^{+}$and $\mathrm{Pip}^{-}$strains of Neisseria meningitidis and Neisseria lactamica have been described (Sperry et al., 1986; Yajko et al., 1984). In this study, we describe the cloning, mapping and characterization of the gene encoding proline iminopeptidase (Pip) from N. gonorrhoeae.

\section{Results and Discussion}

\section{Cloning and nucleotide sequencing of the pip gene}

Six $\mathrm{Pip}^{+}$E. coli clones were identified within a gonococcal DNA cosmid bank using a standard assay for Pip activity. 


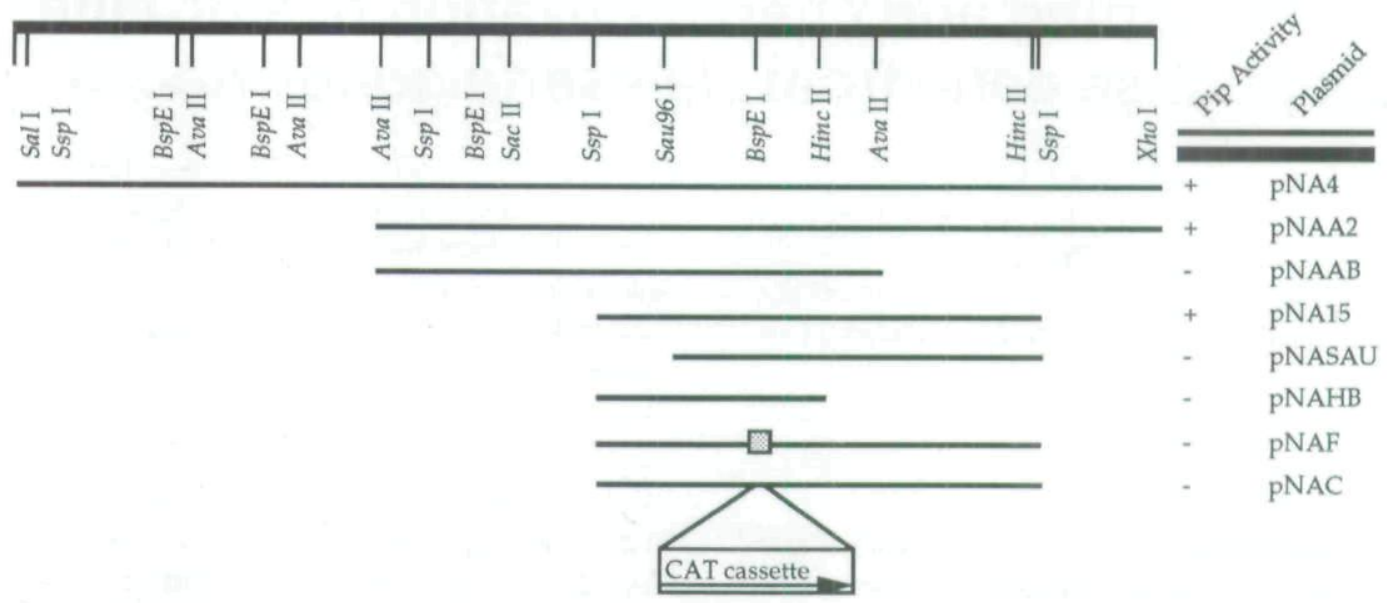

Fig. 1. Partial restriction endonuclease map of the $4 \mathrm{~kb}$ Sall-Xhol fragment carrying Pip activity and subclones generated to assay for Pip in E. coli transformants. Pip activity in transformants was determined by the standard assay. The shaded box indicates the BspE site that was filled in and made blunt-ended with Klenow to generate an 8 bp insertion (pNAF). The chloramphenicol acetyl transferase gene cassette (CAT) was also ligated into the BspEI site as a blunt-ended fragment ( $\mathrm{pNAC}$ ), giving rise to $\mathrm{Cm}^{-}$-resistant $\mathrm{Pip}^{-}$transformants having the CAT gene with the transcriptional orientation as shown.

Digestion of the cosmid DNAs with Clal revealed a common $18 \mathrm{~kb}$ fragment which, when subcloned, was capable of conferring Pip activity on $E$. coli. Further subcloning localized Pip activity to a $4 \mathrm{~kb}$ Sall-Xhol fragment that conferred full Pip activity on the host $E$. coli when cloned in pACYC184 or pBSK (pNA4, Fig. 1). This fragment was cloned into pBSK in both orientations with respect to lac $Z$ transcription. By measuring Pip activity (rate of proline-pnitroanilide hydrolysis) permg total cell protein, a preferential expression of the gene in one orientation was found when transcription was induced by the addition of IPTG (not shown). To further localize the gene, and to construct clones for nucleotide sequencing, both nested deletions and subcloning were used to construct plasmids carrying smaller inserts of gonococcal DNA. Resulting clones were analysed for Pip activity, and a $1.5 \mathrm{~kb}$ Sspl fragment was found to confer full Pip activity on the $E$. coli host (pNA15, Fig. 1). A unique BspEI site was identified on pNA15, which was filled-in and made blunt ended using Klenow enzyme and deoxyribonucleoside triphosphates. E. coli transformants for the religated plasmid were Pip-' Similarly, when a promoterless chloramphenicol acetyltransferase (CAT) gene cassette from pCM7 (Close and Rodriguez, 1982) was cloned into the $B s p E$ I site, the $E$. coli transformants were $\mathrm{Pip}^{-}$and chloramphenicol $(\mathrm{Cm})$ resistant (Fig. 1).

Nucleotide sequencing of the Sspl fragment indicated the presence of a single large open reading frame (ORF) (Fig. 2). The deduced amino acid sequence from this ORF would correspond to a protein of $34.5 \mathrm{kDa}$ having a $\mathrm{pl}$ of 5.4. Upstream of the translational start, a sequence characteristic of a ribosome-binding site (AGAAG, $-8 \mathrm{bp}$, Fig. 2) was found. The ORF corresponds to 311 amino acids and, following the translational stop codon, there is a 12 bp inverted repeat (948-977 bp, Fig. 2) - a motif suggested to act as a transcriptional attenuator or terminator (Yager and von Hippel, 1987). The consensus gonococcal DNA uptake sequence (Goodman and Scocca, 1988) was also found internal to the ORF (406417 bp, Fig. 2).

Sequence analysis of the region surrounding pip revealed no significant ORFs that appeared to be co-transcribed with pip. Northern blot analysis using gonococcal RNA and the Sspl fragment as probe indicated that the size of the transcript was similar in size to the DNA needed to encode the ORF (not shown), thus pip does not appear to belong to an operon.

A database search using the deduced amino acid sequence showed that proline iminopeptidase from $N$. gonorrhoeae and $B$. coagulans share limited regions of homology. In addition, stronger similarities were found between Pip and the active site region of a family of hydrolases from Pseudomonas spp., including atropinesterase (Hessing, 1983) and hydroxymuconic semialdehyde hydrolase (Horn et al., 1991; our unpublished results).

\section{The pip gene product is $35 \mathrm{kDa}$ and has a pl of 5.4}

Analysis by in vitro transcription/translation was used to identify a gene product that could be correlated to Pip activity and the ORF. The results from this analysis on 


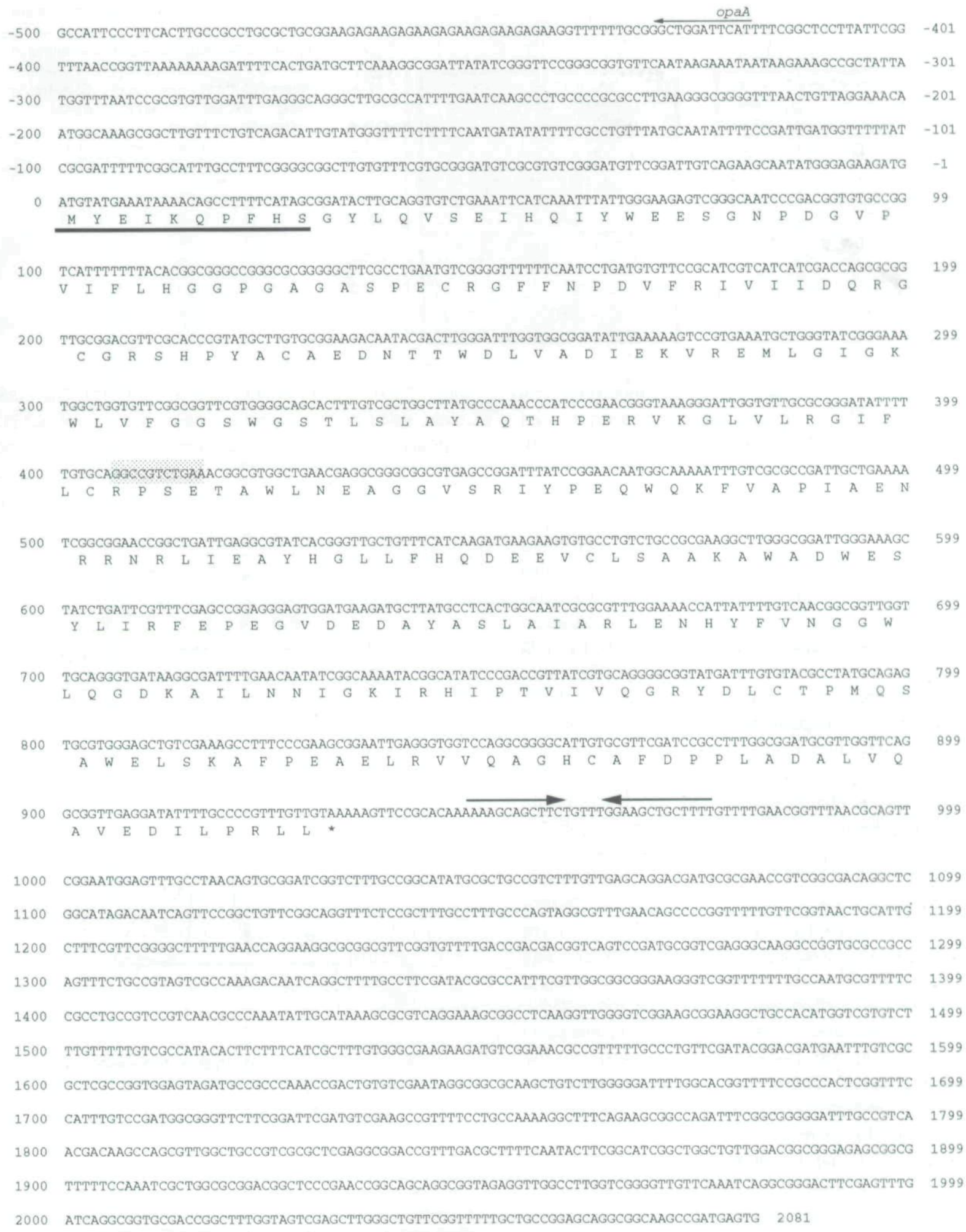

Fig. 2. Nucleotide sequence of the proline iminopeptidase gene and the deduced amino acid sequence of the ORF. The nucleotide sequence is numbered from the $5^{\prime}$ end of the sequenced fragment. Amino acid sequence of the protein determined by Edman degradation is underlined. Translational start of the opaA gene is at position -419 relative to pip. The $10 \mathrm{bp}$ gonococcal uptake sequence is shaded. A putative transcriptional terminator is indicated by arrows. These sequence data appear in the EMBL/GenBank/DDBJ Nucleotide Sequence Data Libraries under the accession number Z25461. 


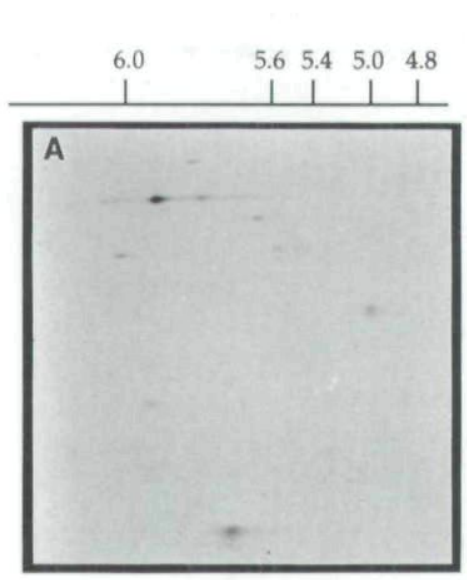

pI

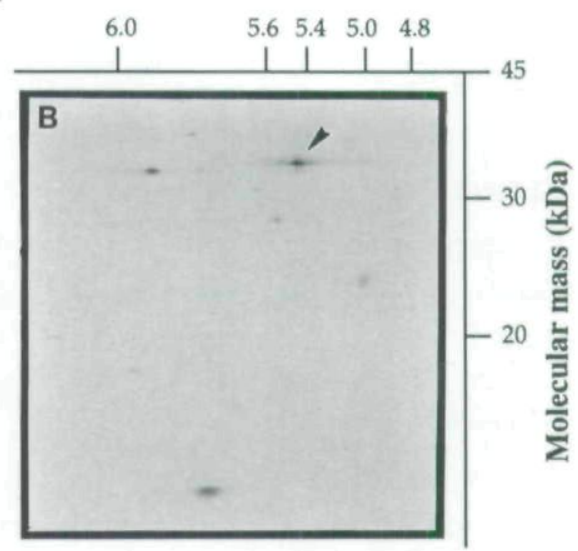

Fig. 3. In vitro coupled transcription/translation analysis of pBSK (A) and pNA15 (B) as analysed by 2-D SDS-PAGE. Molecular mass and pl of known proteins are indicated. Proteins were labelled by the incorporation of $\left[{ }^{35} \mathrm{~S}\right]$-methionine using an $\mathrm{S} 30$ extract. The pip gene product is indicated by an arrow.
pBSK (A) and pNA15 (B) as analysed by two-dimensional (2-D) SDS-PAGE are shown in Fig. 3, indicating that the gonococcal DNA insert encodes a protein with a molecular mass of $35 \mathrm{kDa}$, having a pl of 5.4 . Furthermore, in vitro transcription/translation products were analysed for Pip activity by the addition of pro-pNA to the in vitro assay. Only in the presence of pNA15 was there detectable Pip activity (not shown). To confirm the identity of the Pip protein with the predicted ORF, we overexpressed Pip by IPTG induction of an E. coli strain harbouring pNA15, separated the proteins by 2-D SDS-PAGE, and performed automated $N$-terminal sequencing directly on the protein blotted to a PVDF membrane (see the Experimental procedures for details). The $\mathrm{N}$-terminal sequence obtained from the analysis (M Y E I K Q P F H S G) matched perfectly the ORF predicted in Fig. 2. The Pip gene product was also identified on Coomassie brilliant blue-stained one-dimensional SDSPAGE gels from protein extracts of $E$. coli cells carrying pNA15 and induced by IPTG (Fig. 4B). In comparison with cells carrying only the vector plasmid, a new $35 \mathrm{kDa}$ protein band was detected. Proteins from identical gels were blotted to a nitrocellulose membrane. The membrane was then sliced into fractions based on molecular weight, which were then individually assayed for Pip activity. Maximum activity was found to coincide with the band corresponding to the overexpressed product on the stained gel (Fig. 4A). Together, these results clearly indicate that the gene encoding Pip is present on the Sspl fragment, that the gene product has a molecular mass of $35 \mathrm{kDa}$, and that no additional gonococcal DNA sequences are required for its expression in E. coli.

\section{pip maps adjacent to opaA on the MS11 chromosome}

Computer-assisted database searching revealed that the region upstream and on the opposite DNA strand from the pip gene had been previously characterized, with the DNA sequence found here being identical to that of the
opaA gene of strain MS11 (Bhat et al., 1991). The nucleotide sequence comprising the characteristic СTTCT repeats and the translational start of this particular opa locus (482 bp upstream of pip, Fig. 2) is previously unpublished. The DNA homology between opaA and the other

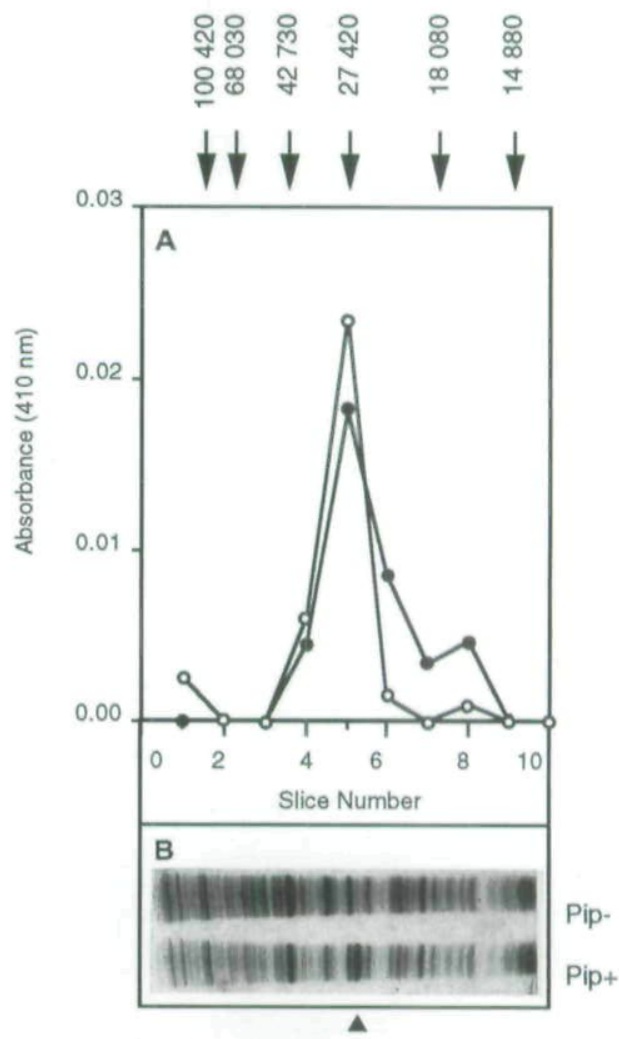

Fig. 4. Pip activity in discrete fractions of proteins separated by SDS-PAGE.

A. Identical gels were blotted to nitrocellulose and fractionated into $5 \mathrm{~mm}$ slices. Each slice was individually assayed for Pip activity by measuring the hydrolysis of pro-pNA at $410 \mathrm{~nm}$. The absorbance of the corresponding slice of the control was subtracted from the Pip ${ }^{+}$samples. The molecular mass $(\mathrm{Da})$ of size markers is indicated. The different symbols denote results from separate experiments.

B. One-dimensional SDS-PAGE gels of protein extracts from E. coli overexpressing pNA15 ( $\left.\mathrm{Pip}^{+}\right)$and control (pBSK, Pip ). The pip gene product is indicated. 
A

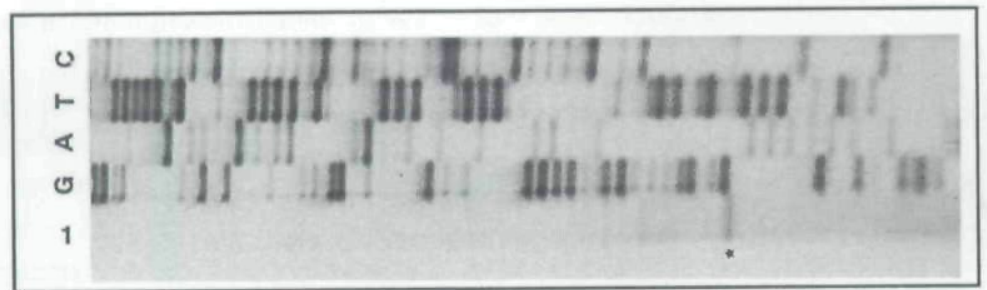

B

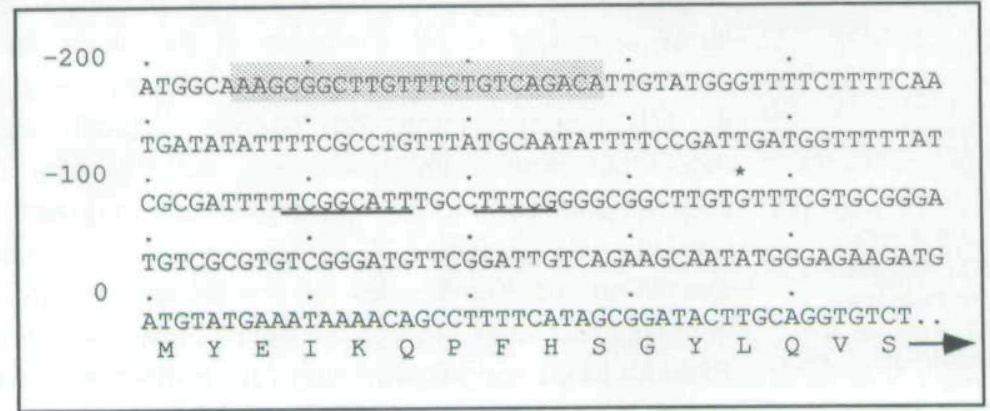

Fig. 5. Identification of the pip promoter. A. Primer extension analysis of RNA isolated from log-phase $E$. coli expressing Pip from pNA4 (lane 1). Sequencing ladder generated from pNA4 using the same primer.

B. Sequence of the pip promoter and upstream activation site (UAS). The $\sigma^{54}$ recognition site is underlined, the UAS is shaded, the transcription start site is indicated. opa loci is conserved up to the -35 sequence of the putative promoter of the other opa genes (at -332 relative to pip), but opaA shares no further upstream sequence homology with the other 10 loci described in N. gonorrhoeae strain MS11 (Bhat et al., 1991). Like the other opa loci studied in an $E$. coli background, the translational start of opaA is out-of-frame with the mature protein. In addition, the opaA gene product was not seen on in vitro transcription/translation assays of pNA4, which contain the entire OpaA coding region (not shown). The opaA gene has been mapped to a $55 \mathrm{~kb}$ fragment on the chromosome of strain MS11-N198 (fragment nK; Bihlmaier et al., 1991), thus the pip gene was localized to this position on the gonococcal chromosome.

\section{Transcription of pip initiates near an ntrA-like promoter} sequence in $\mathrm{E}$. coli

Examination of the region upstream of the translational start of pip revealed no significant homology to typical -10 or -35 consensus promoter sequences. However, sequences reminiscent of promoters requiring the sigma factor encoded by the ntrA gene $\left(\sigma^{54}\right)$ product for transcription were identified. This sequence, upstream of pip (GG- $\mathrm{N}_{10}-\mathrm{TC}$ ) is identical to the NtrA-dependent $\mathrm{glnH}$ 2 promoter in E. coli (Claverie-Martin and Magasanik, 1991), but not to the consensus sequence ( $\left.G G-N_{10}-G C\right)$ which has been found at -24 and -12 , with respect to the transcription initiation site in almost all the other NtrAdependent systems (Kustu et al., 1989). The transcriptional start of pip was determined by primer extension on RNA isolated from $E$. coli carrying pNA4, which has $2 \mathrm{~kb}$ of gonococcal DNA $5^{\prime}$ of the pip gene. The primer used in the extension shown in Fig. 5 is complementary to bases
-9 to -26 in Fig. 2. The result of this analysis indicated that the $5^{\prime}$ end of the transcript initiated at position -63 and that the ntrA-like sequences were positioned -16 and -28 relative to the start site. The pip promoter sequence shows good homology to the pilin gene promoters in both N. gonorrhoeae (Meyer et al., 1984) and Pseudomonas aeruginosa, and which in the latter case has been shown to be dependent on NtrA for its transcription (Ishimoto and Lory, 1989). NtrA-dependent genes require, in addition to the sequences at -24 and -12 , the binding of an activator protein (NtrC, NifA homologue) to upstream sequences for transcription to be initiated (Kustu et al., 1989). A sequence similar to the consensus (G/A- $\mathrm{N}_{7}-\mathrm{TGT}-\mathrm{N}_{4}-\mathrm{T}-$ $\mathrm{N}_{5}-\mathrm{ACA}$ ) for NifA binding was found -194 bp relative to the mRNA start site of pip $\left(A-N_{7}-T G T-N_{3}-T-N_{5}-A C A\right)$.

\section{Gonococcal Pip mutants have no residual proline iminopeptidase activity}

To determine if the pip gene identified from the cloning experiments was responsible for Pip activity detected in gonococci, gonococcal mutants carrying defined lesions in the pip locus were constructed. pNAC was digested to release a fragment containing the entire pip gene, including the 700 bp CAT gene cassette. When gonococci were transformed with this DNA, resultant $\mathrm{Cm}$-resistant transformants were found to lack Pip activity, as determined by the standard assay. This indicates that Pip activity is nonessential for growth in the background of a gonococcal proline prototroph. Chromosomal DNA was isolated from the transformants and analysed by Southern hybridization using the Sspl fragment as the probe (Fig. 6). In comparison with the wild-type DNA, the Sspl probe hybridized to a larger Clal fragment in the two mutants, and because 


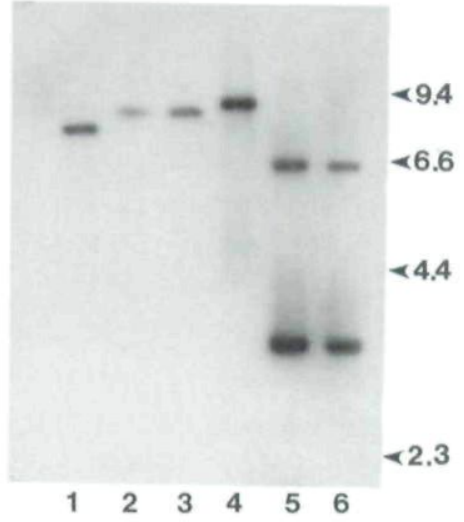

Fig. 6. Southern hybridization of gonococcal chromosomal DNA digested with Cla I (lanes 1-3) and EcoRI (lanes 4-6) from wild type (lanes 1 and 4) and $\mathrm{Cm}$-resistant, $\mathrm{Pip}^{-}$transformants (lanes 2, 3, 5, 6). The filters were probed using the $1.5 \mathrm{~kb} S s p l$ fragment from pNA15. The CAT cassette contains no Clal sites and one EcoRI site. DNA size markers in kb are indicated.

of the EcoRl site within the CAT cassette, two fragments in the EcoRl digests in the mutants bound the probe. These results also show that only one copy of pip is present on the MS11 chromosome.

\section{Pip releases biologically active proline from pro-gly}

In addition to hydrolysing pro-pNA, the ability of Pip to hydrolyse the dipeptide pro-gly was investigated. An assay was devised based on the observation that $E$. coli proline auxotrophs that carry a mutation in the $d p p A$ (dipeptide permease) locus are unable to utilize the dipeptide pro-gly as a source of proline since they are unable to transport pro-gly into the cytoplasm (Olson et al., 1991, Fig. 7B). These strains were transformed with vector (pACYC184, Fig. 7C) or Pip-expressing plasmids (pNAA2, Fig. 7D) and grown in M9 minimal media supplied with either proline or pro-gly as proline source. In comparison with the proC mutants (Fig. $7 \mathrm{~A}$ ), the proC $d p p A$ mutants were able to utilize pro-gly as a proline source only when transformed with Pip-expressing plasmids. This experiment might suggest that when expressed from a medium-copy-number plasmid (pACYC184 derivative), some Pip activity is located outside the cytoplasm in $E$. coli. This activity may instead be a result of the lysis of a few cells. Thus, stronger evidence points to the fact that Pip is a cytoplasmic protein in gonococci since cell fractions analysed for Pip activity indicated that the cytoplasm held the greatest activity of Pip permg protein (not shown). Also, no typical $\mathrm{N}$-terminal processing, as is common for proteins targeted for export from the cytoplasm, has been detected and the protein expressed in E. coli has the same molecular mass as the product identified in the in vitro transcription/translation assay.

In summary, we have cloned and characterized the gene encoding proline iminopeptidase from N. gonorrhoeae. Primer extension analysis indicated that the pip gene in $E$. coli is transcribed from an NtrA-like promoter and a sequence similar to the NifA-binding consensus sequence was located $194 \mathrm{bp}$ upstream of the transcriptional start site of pip. Because of the close linkage between opaA and pip, we were also able to map pip on the MS11 chromosome. Pip ${ }^{-}$gonococci, totally lacking detectable proline iminopeptidase activity were constructed and found to be indistinguishable in growth rate from the wild-type strain. Future studies will be aimed at examining the significance of the limited amino acid homology between Pip and the family of hydrolases from Pseudomonas spp., determining if pip transcription is regulated in response to growth conditions, and at understanding the possible role of pip in proline metabolism during growth and survival in the host.

\section{Experimental procedures}

\section{Bacterial strains and plasmids}

N. gonorrhoeae strain MSO1-1X (Zhang et al., 1992), a derivative of MS11 $1_{\mathrm{ms}}$ was cultivated as previously described (Swanson et al., 1985). E. coli strains HB101 and $\mathrm{DH} 5 \alpha$ were used as recipients for recombinant plasmids. E. coli W3110 derivatives $\mathrm{E} 1769$ (proC) and $\mathrm{E} 1614$ (proC and $d p p A$ ) were kindly supplied by E. Olson. Vectors used were pACYC184 (NEB) and pBluescript SK/KS II+ (pBSK, pBKS, Stratagene). E. coli were grown in LB medium (Sambrook et al., 1989) or M9 minimal medium (Miller, 1982) at $37^{\circ} \mathrm{C}$ supplemented with chloramphenicol $\left(10 \mu \mathrm{g} \mathrm{ml}^{-1}\right)$ or carbenicillin $\left(50 \mu \mathrm{g} \mathrm{ml}^{-1}\right)$ and X-gal $(0.8$ $\mathrm{mg}$ per plate) when appropriate. E. coli and gonococcal cells were fractionated into periplasmic, cytoplasmic and membrane fractions according to Achtman et al. (1983).

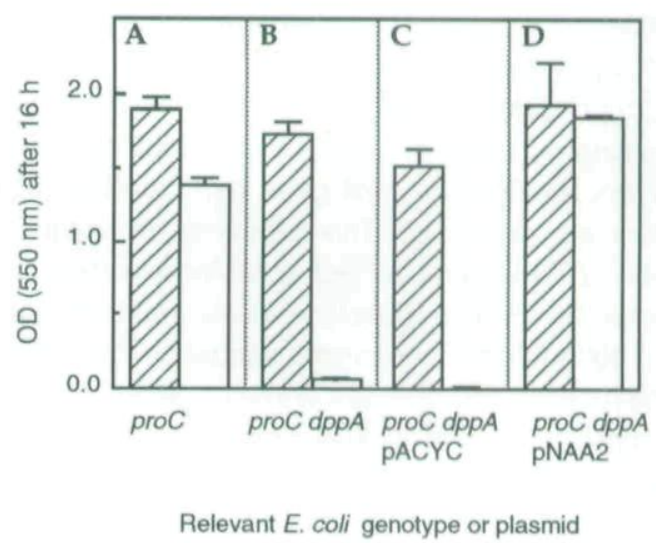

Fig. 7. Growth of $\operatorname{pro} C(\mathrm{~A})$ and $p r o C d p p A$ mutants of $E$. coli transformed with no (B), vector (C), or Pip-expressing (D) plasmids in M9 minimal media supplemented with proline $(\square)$ or pro-gly $(\square)$ at $0.4 \mathrm{mM}$. 


\section{Molecular cloning and sequencing procedures}

DNA purifications, ligations, restriction analysis, gel electrophoresis, primer extension and Southern and Northern hybridizations were prepared according to Sambrook et al. (1989). RNA was extracted from gonococci according to Bergström et al. (1986). Double-stranded nested deletions were constructed using a kit from Pharmacia for that purpose. Templates for double-stranded DNA sequencing were prepared according to Ausubel et al. (1987), or by using Qiagen midi columns (Qiagen, Inc). The protocol for annealing primers to templates was performed according to Su et al. (1991). Briefly, $2 \mu \mathrm{g}$ plasmid DNA in a microcentrifuge tube was dried in a speed vacuum concentrator. Two microlitres $0.20 \mathrm{~N} \mathrm{NaOH}$ was added to the DNA pellet and the tube was maintained at room temperature for 2 to $3 \mathrm{~min}$. The following were then added in sequence: $2.0 \mu \mathrm{l}$ primer $\left(2.5 \mathrm{ng} \mu \mathrm{l}^{-1}\right), 2.0 \mu \mathrm{l} \mathrm{H}_{2} \mathrm{O}$ and $2.0 \mu \mathrm{l}$ annealing buffer $(833 \mathrm{mM}$ Tris, $\mathrm{pH} 7.5$, and $83 \mathrm{mM}$ $\mathrm{MgCl}_{2}$ ). After $2 \mathrm{~min}$ at room temperature, $2 \mu \mathrm{l} 0.2 \mathrm{~N} \mathrm{HCl}$ was added and the tube was incubated for $2 \mathrm{~min}$ at room temperature. DNA sequencing was performed directly on these samples using the Sanger dideoxy chain termination method with $\left[{ }^{35}\right.$ S]-ATP and Sequenase (USB) according to the manufacturer's instructions. Sequences were stored, matched and analysed using MacVector software and the Wisconsin Genetics Computer Group package.

In vitro transcription/translation analysis of plasmids was performed using the Promega E. coli S30 coupled transcription/translation system. Non-radioactive assays were prepared by using the complete premix supplied in the kit.

\section{One-dimensional SDS-PAGE}

Conditions for SDS-PAGE and electroblotting were as described previously (Koomey et al., 1991) using the Mini-Protean gel and transfer system (Hoeffer Scientific Instruments).

\section{Two-dimensional SDS-PAGE and sample preparation for protein microsequencing}

Cultures of $E$. coli $\mathrm{DH} 5 \alpha$ carrying pNA15 were grown in LB to log phase and induced for Pip synthesis by the addition of $0.4 \mathrm{mM}$ IPTG for $1 \mathrm{~h}$. Cell extracts for two-dimensional polyacrylamide gels were prepared by the method of O'Farrell (1975) with modifications (VanBogelen et al., 1990). After electrophoresis, the gels were soaked in transfer buffer (10 mM 3[cyclohexylamino]-1-propanesulphonic acid, 10\% methanol, $\mathrm{pH} 11.0$ ) for $10 \mathrm{~min}$ to reduce the amount of Tris and glycine contaminations. Polyvinylidene diflouride (PVDF; Immobilon, Millipore) membranes were rinsed with $100 \%$ methanol and stored in transfer buffer. The gels, sandwiched between sheets of PVDF membrane and several sheets of Whatman paper, were assembled into a blotting apparatus and electroeluted for $30 \mathrm{~min}$ at $50 \mathrm{~V}(170-100 \mathrm{~mA})$ in transfer buffer. The PVDF membranes were rinsed in sterile deionized water for $10 \mathrm{~min}$, then stained with $0.1 \%$ Coomassie brilliant blue in $50 \%$ methanol for $5 \mathrm{~min}$. After destaining (50\% methanol, $10 \%$ acetic acid), and rinsing with deionized water, the protein spot representing Pip was identified and excised from the blot. Determination of the $\mathrm{N}$-terminal amino acid sequence of the Pip protein was performed by automated Edman degradation directly on the membrane fragment (University of Michigan Medical School core facility).

\section{Primer extension}

Oligonucleotide primers complementary to bases -9 to -26 (Fig. 2) were end-labelled by using $50 \mu \mathrm{Ci}$ of $\left[\gamma^{32} \mathrm{P}\right]-\mathrm{ATP}$ $\left(5000 \mathrm{Cimmol}^{-1}\right)$ and T4 polynucleotide kinase as described by Sambrook et al. (1989). Labelled primer $(50 \mathrm{pmol})$ was mixed with RNA $(60 \mu \mathrm{g})$ prepared from E. coli $\mathrm{DH} 5 \alpha$ harbouring pNA4, heated to $85^{\circ} \mathrm{C}$ for $10 \mathrm{~min}$ and annealed at $50^{\circ} \mathrm{C}$ for $12 \mathrm{~h}$. The primer:RNA hybrids were precipitated and resuspended for reverse transcriptase reactions as described by Sambrook et al. (1989). The primer extension reaction mixtures were subjected to electrophoresis next to a sequencing ladder generated using the same primer in $8 \%$ polyacrylamide gels containing $8 \mathrm{M}$ urea followed by autoradiography.

\section{Proline iminopeptidase assay}

Proline iminopeptidase was assayed by monitoring the hydrol$y$ sis of the chromogenic substrate proline-p-nitroanilide (propNA, Sigma). Gonococci or E. coli transformants were assayed for Pip activity by resuspending cells in $200 \mu \mathrm{l}$ PBS containing $0.019 \mathrm{mM}$ pro-pNA in a microtitre well and looking for the visible change to a yellow colour. For kinetic analysis, the rate of change in absorbance at $410 \mathrm{~nm}$ owing to the hydrolysis of propNA was assayed and normalized to the amount of protein in the assay. Although proline iminopeptidase activity has been described in E. coli K-12 (Sarid et al., 1959), this activity was too low to interfere with these studies. The Pip activity of proteins blotted to nitrocellulose from a one-dimensional SDS-PAGE gel was determined by taking $5 \mathrm{~mm}$ slices of the membrane and placing them in tubes containing $1.5 \mathrm{ml} 10 \mathrm{mM}$ Tris ( $\mathrm{pH} 7.8$ ) containing $0.019 \mathrm{mM}$ pro-pNA. After $24 \mathrm{~h}$, the absorbance at $410 \mathrm{~nm}$ was measured, and compared with the activity of the corresponding slice from cells harbouring only pBSK.

\section{Functional assay of Pip on pro-gly}

To determine if the hydrolysis of Pip on the dipeptide pro-gly resulted in free, biologically active proline, E. coli strains mutant in proline biosynthesis (proC) and uptake of dipeptides $(d p p A)$ were utilized. Strain E1772 carries both mutations and is therefore unable to grow on pro-gly as its sole source of proline (Olson et al., 1991). Pip-expressing plasmids (pACYC184 derivative pNAA2) were transformed into E1772, and assayed for Pip activity by the hydrolysis of pro-pNA, and these strains were then grown in M9-glucose medium containing either proline $(0.4 \mathrm{mM})$ or pro-gly $(0.4 \mathrm{mM})$ as proline source. Cultures were grown aerobically for $16 \mathrm{~h}$ at $37^{\circ} \mathrm{C}$ and the optical density at $550 \mathrm{~nm}$ was measured.

\section{Gonococcal transformation}

Gonococci were transformed with linearized pNAC $\left(10 \mu \mathrm{g} \mathrm{ml}^{-1}\right)$ by resuspending cells grown for $15 \mathrm{~h}$ on plates in preincubated $\left(37^{\circ} \mathrm{C}, 5 \% \mathrm{CO}_{2}\right)$ liquid medium $\left(10^{8}\right.$ cells $\left.\mathrm{ml}^{-1}\right)$ containing $7 \mathrm{mM}$ $\mathrm{MgCl}_{2}$. After incubation at $37^{\circ} \mathrm{C}$ for $30 \mathrm{~min}$, the suspension was 
diluted 30 -fold and incubated for $5 \mathrm{~h}$ with tumbling to allow for expression of $\mathrm{Cm}$ resistance. Cultures were plated on $\mathrm{Cm}$ gradient plates and incubated at $37^{\circ} \mathrm{C}$. Transformants were identified as large colonies in the area of high concentrations of $\mathrm{Cm}$, and streaked onto $\mathrm{Cm}\left(5 \mu \mathrm{g} \mathrm{ml}^{-1}\right)$ plates. These were tested for Pip activity, and chromosomal DNA was prepared from them for Southern hybridization.

\section{Acknowledgements}

The authors greatly appreciate the help received from T. Nyström with respect to two-dimensional gel electrophoresis. M.K. is a Pew Scholar in the Biomedical Sciences. N.H.A. was supported by NIH training grant 5 T32 Al 07360 , and was the recipient of travel stipend 9211-301 from the Swedish Natural Science Research Council.

\section{References}

Achtman, M., Mercer, A., Kusecek, B., Pohl, A., Heuzenroeder, M., Aaronson, W., Sutton, A., and Silver, R.P. (1983) Six widespread bacterial clones among Escherichia coli $\mathrm{K} 1$ isolates. Infect Immun 39: 315-335.

Ausubel, F.M., Brent, R., Kingston, R.E., Moore, D.D., Seidman, J.G., Smith, J.A., and Struhl, K. (1987) Current Protocols in Molecular Biology. New York: John Wiley and Sons.

Bergström, S., Robbins, K., Koomey, J.M., and Swanson, J. (1986) Piliation control mechanisms in Neisseria gonorrhoeae. Proc Natl Acad Sci USA 83: 3890-3894.

Bhat, K.S., Gibbs, C.P., Barrera, O., Morrison, S.G., Jahnig, F., Stern, A., Kupsch, E.M., Meyer, T.F., and Swanson, J. (1991) The opacity proteins of Neisseria gonorrhoeae strain MS11 are encoded by a family of 11 complete genes. Mol Microbiol 5: 1889-1901 (erratum: Mol Microbiol 6: 10731076).

Bihlmaier, A., Römling, U., Meyer, T.F., Tümmler, B., and Gibbs, C.P. (1991) Physical and genetic map of the Neisseria gonorrhoeae strain MS11- N198 chromosome. Mol Microbio/ 5: 2529-2539.

Chen, K.C., and Buchanan, T.M. (1980) Hydrolases from Neisseria gonorrhoeae. The study of gonocosin, an aminopeptidase-P, a proline iminopeptidase, and an asparaginase. $J$ Biol Chem 255: 1704-1710.

Claverie-Martin, F., and Magasanik, B. (1991) Role of integration host factor in the regulation of the ginHp2 promotor of Escherichia coli. Proc Natl Acad Sci USA 88: 1631-1635.

Close, T.J., and Rodriguez, R.L. (1982) Construction and characterization of the chloramphenicol-resistance gene cartridge: a new approach to the transcriptional mapping of extrachromosomal elements. Gene 20: 305-316.

D'Amato, R.F., Enriquez, K.M., Tomfohrde, K.M., and Singerman, E. (1978) Rapid identification of Neisseria gonorrhoeae and Neisseria meningitidis by using enzymatic profiles. J Clin Microbiol 7: 77-81.

Goodman, S.D., and Scocca, J.J. (1988) Identification and arrangement of the DNA sequence recognized in specific transformation of Neisseria gonorrhoeae. Proc Natl Acad Sci USA 85: 6982-6986.

Hessing, J.G.M. (1983) The primary structure of atropinesterase from Pseudomonas putida. Ph.D. Thesis. The Netherlands: University of Leiden.

Horn, J.M., Harayama, S., and Timmis, K.N. (1991) DNA sequence determination of the TOL plasmid (pWWO) $x y l-$ GFJ genes of Pseudomonas putida: implications for the evolution of aromatic catabolism. Mol Microbiol 5: 2459-2474.

Ishimoto, K.S., and Lory, S. (1989) Formation of pilin in Pseudomonas aeruginosa requires the alternative sigma factor (RpoN) of RNA polymerase. Proc Natl Acad Sci USA 86: 1954-1957.

Kitazono, A., Yoshimoto, T., and Tsuru, D. (1992) Cloning, sequencing and high expression of the proline iminopeptidase gene from Bacillus coagulans. I Bacteriol 174: 7919-7925.

Knapp, J.S., and Holmes, K.K. (1975) Disseminated gonococcal infections caused by Neisseria gonorrhoeae with unique nutritional requirements. $J$ Inf Dis 132: 204-208.

Koomey, M., Bergström, S., Blake, M., and Swanson, J. (1991) Pilin expression and processing in pilus mutants of Neisseria gonorrhoeae: critical role of Gly ${ }_{-1}$ in assembly. Mol Microbiol 5: 279-287.

Kustu, S., Santero, E., Keener, J., Popham, D., and Weiss, D. (1989) Expression of $\sigma^{54}$ (ntrA)-dependent genes is probably united by a common mechanism. Microbiol Rev 53: 367-376.

Mäkinen, K.K. (1969) The proline iminopeptidases of the human oral cavity. Acta Chem Scand 23: 1409-1438.

Meyer, T.F., Billyard, E., Hass, R., Storzbach, S., and So, M. (1984) Pilus genes of Neisseria gonorrhoeae: chromosomal organization and DNA sequence. Proc Natl Acad Sci USA 81: 6110-6114.

Miller, J.H. (1982). Experiments in Molecular Genetics. Cold Spring Harbor, New York: Cold Spring Harbor Laboratory Press.

O'Farrell, P.H. (1975) High resolution two-dimensional electrophoresis of proteins. J Biol Chem 250: 4007-4021.

Olson, E.R., Dunyak, D.S., Jurss, L.M., and Poorman, R.A. (1991) Identification and characterization of $d p p A$, an Escherichia coli gene encoding a periplasmic dipeptide transport protein. J Bacteriol 173: 234-244.

Sambrook, J., Fritsch, E.J., and Maniatis, T. (1989) Molecular Cloning: A Laboratory Manual. Cold Spring Harbor, New York: Cold Spring Harbor Laboratory Press.

Sarid, S., Berger, A., and Katchalski, E. (1959) Proline iminopeptidase. J Biol Chem 234: 1740-1746.

Sarid, S., Berger, A., and Katchalski, E. (1962) Proline Iminopeptidase: purification and comparison with iminodipeptidase (prolinase). J Biol Chem 237: 2207-2212.

Sperry, J.F., Cohenford, M.A., Campognone, P., Lawton, W., and Chee, D.O. (1986) Increased detection of prolylaminopeptidase in Neisseria meningitidis by Identicult-Neisseria. J Clin Microbiol 24: 145-145.

Su, Y.A., Sulavik, M.C., He, P., Makinen, K.K., Makinen, P.L., Fiedler, S., Wirth, R., and Clewell, D.B. (1991) Nucleotide sequence of the gelatinase gene (gelE) from Enterococcus faecalis subsp. liquefaciens. Infect Immun 59: 415-420.

Swanson, J., Bergström, S., Barrera, O., Robbins, K., and Corwin, D. (1985) Pilus ${ }^{-}$gonococcal variants. Evidence for multiple forms of piliation control. J Exp Med 162: 729-744.

VanBogelen, R.A., Hutton, M.E., and Neidhardt, F.C. (1990) Gene-protein database of Escherichia coli K-12: edition 3. Electrophoresis 11: 1131-1166.

Yager, T.D., and von Hippel, P.H. (1987) Transcript elongation and termination in Escherichia coli. In Escherichia coli and Salmonella typhimurium: Cellular and Molecular Biology. Vol. 2. Neidhardt, F.C., Ingraham, J.L., Low, L.B., Magasanik, B., Schaechter, M., and Umbarger, H.E. (eds). Wash- 
ington, D.C.: American Society for Microbiology, pp. $1241-1275$.

Yajko, D.M., Chu, A., and Hadley, W.K. (1984) Rapid confirmatory identification of Neisseria gonorrhoeae with lectins and chromogenic substrates. J Clin Microbiol 19: 380-382.

Yoshimoto, T., and Tsuru, D. (1985) Proline iminopeptidase from Bacillus coagulans: Purification and enzymatic properties. J Biochem 97: 1477-1485.
Yoshimoto, T., Saeki, S., and Tsuru, D. (1980) Proline iminopeptidase from Bacillus megaterium: purification and characterization. J Biochem 93: 469-477.

Zhang, Q.Y., DeRyckere, D., Lauer, P., and Koomey, M. (1992) Gene conversion in Neisseria gonorrhoeae: evidence for its role in pilus antigenic variation. Proc Natl Acad Sci USA 89: 5366-5370. 
This document is a scanned copy of a printed document. No warranty is given about the accuracy of the copy. Users should refer to the original published version of the material. 